\title{
Impacto do Confinamento em Crianças e Adolescentes
}

\section{The Impact of Confinement on Children and Adolescents}

Filipa PEDRO DOS REIS $\square^{1,2}$, Rita AMARO 2,3 , Filipa MARTINS SILVA ${ }^{2,4}$, Sofia VAZ PINTO ${ }^{2,3}$, Inês BARROCA ${ }^{2,5}$, Teresa SÁ ${ }^{2,4}$, Rui FERREIRA CARVALHO ${ }^{2,6}$, Teresa CARTAXO ${ }^{1,2}$, José BOAVIDA 7,8

Acta Med Port 2021 Apr;34(3):245-246 - https://doi.org/10.20344/amp.15854

Palavras-chave: Adolescente; COVID-19; Criança; Pandemia; Portugal; Quarentena/psicologia; Saúde Mental

Keywords: Adolescent; Child; COVID-19; Mental Health; Pandemics; Portugal; Quarantine/psychology

Em resposta à disseminação acentuada da doença provocada pelo novo coronavírus (COVID-19) em Portugal, o Governo ordenou em janeiro de 2021 um novo encerramento dos estabelecimentos de ensino e de tempos-livres, concomitante com o dever de recolhimento obrigatório a toda a população. É possível fazer um paralelo das implicações destas medidas restritivas na saúde dos bebés, crianças e adolescentes, com base no observado a nível nacional e internacional durante a primeira vaga, ainda que seja impossível prever as consequências a longo-prazo.

Nos primeiros anos de vida, a criança regista um ritmo de crescimento e desenvolvimento incomparáveis, com uma procura ativa de experiências, comunicação e relação, imprescindíveis à sua maturação cognitiva, psicoafectiva e social. Em confinamento, ficaram restritas ao ambiente familiar, com uma rede relacional limitada, e muitas vezes com pais divididos entre a gestão das atividades laborais e a prestação de cuidados, o que limitou a oferta de experiências neste período de ouro do desenvolvimento. Deste modo, na primeira vaga, crianças de ambientes socioeconómicos desfavoráveis ou com pais pouco disponíveis foram as mais afetadas pelo encerramento das creches e jardins-de-infância, decorrente da inacessibilidade a um ambiente que permite uma ampla rede de relações sociais num espaço estimulante e promotor do desenvolvimento. ${ }^{1}$

Adicionalmente, a exaustão parental levou a uma maior incidência de perturbações de ansiedade e depressivas nos cuidadores, com sensação de menor competência parental e maior atribuição de emoções negativas às crianças. Ainda assim, o período de recolhimento foi considerado por alguns pais como tendo um impacto positivo, possibilitando um olhar diferente sobre o bebé e a criança pequena e uma oportunidade de reinvenção e reinvestimento na relação pais-filhos. ${ }^{1}$

Nas crianças em idade escolar, em que a autonomia ainda não é expectável, o ensino à distância no primeiro confinamento apresentou alguns desafios ${ }^{1,2}$ : ausência de interação direta com o professor e restante ambiente escolar (prejudicando competências de aprendizagem e sociais), declínio do interesse e foco, falta de tempo e de conhecimento dos pais para apoiar o estudo, sendo tudo isto particularmente preocupante em crianças com dificuldades de aprendizagem que se viram privadas do acompanhamento especializado. Muitas crianças foram afastadas fisicamente de figuras de referência, como os avós, que tinham um papel ativo no seu desenvolvimento social e emocional. ${ }^{2}$ Globalmente, concluiu-se que esta disrupção da estrutura normativa levou a um aumento do nível de stress e da incidência de perturbações do humor e de ansiedade nesta faixa etária, com maior impacto nas crianças com perturbações prévias.

Os adolescentes, em período de autonomização e formação de identidade, com tarefas de independência relativamente aos pais e de proximidade aos pares, viram-se obrigados a contrariar estes movimentos normativos e, embora recorrendo a formas alternativas e seguras de se relacionar à distância, relataram falta de conexão emocional, intimidade e suporte social. ${ }^{3}$

Sendo este período da adolescência também caracterizado por oscilações de humor rapidamente reversíveis, com os stressores relacionados com a pandemia (tais como preocupação com a infeção, com o desconhecido e com o isolamento) estas manifestações normativas agravaram-se, com casos de descompensação psicopatológica. Este risco pareceu ser sobretudo importante nas situações onde se havia verificado problemas de saúde mental prévios ou circunstâncias sociofamiliares adversas. ${ }^{3}$ Paralelamente, com os adultos também em maior vulnerabilidade psicológica, a conflitualidade normativa da relação pais-adolescentes intensificou-se, potenciando situações de

\footnotetext{
1. Serviço de Pedopsiquiatria. Hospital Pediátrico de Coimbra. Centro Hospitalar e Universitário de Coimbra. Coimbra. Portugal.

2. Associação Nacional de Internos de Psiquiatria da Infância e da Adolescência. Lisboa. Portugal.

3. Serviço de Pedopsiquiatria. Hospital de Dona Estefânia. Centro Hospitalar Universitário de Lisboa Central. Lisboa. Portugal.

4. Serviço de Pedopsiquiatria. Centro Materno-Infantil do Norte. Centro Hospitalar e Universitário do Porto. Porto. Portugal.

5. Serviço de Pedopsiquiatria. Hospital de S. Francisco Xavier. Centro Hospitalar de Lisboa Ocidental. Lisboa. Portugal.

6. Serviço de Pedopsiquiatria. Hospital Santa Maria / Hospital Pulido Valente. Centro Hospitalar Universitário Lisboa Norte. Lisboa. Portugal.

7. Centro de Desenvolvimento da Criança. Hospital Pediátrico de Coimbra. Centro Hospitalar e Universitário de Coimbra. Coimbra. Portugal.

8. Sociedade Portuguesa de Défice de Atenção. Coimbra. Portugal.

$\square$ Autor correspondente: Filipa Pedro dos Reis. investigacao.anipia@gmail.com

Recebido: 01 de fevereiro de 2021 - Aceite: 09 de fevereiro de 2021 - Online issue published: 01 de abril de 2021

Copyright @ Ordem dos Médicos 2021
} 
tensão e de violência intrafamiliar. ${ }^{3}$

Transversalmente a todas as faixas etárias, foi descrito um decréscimo dos níveis de atividade física e desregulação dos padrões de sono durante o confinamento, muitas vezes associados a um maior tempo de exposição a ecrãs, alimentação menos variada e com produtos menos fres$\cos ,{ }^{2,4}$ contribuindo para o potencial aumento da obesidade infantil.

Importa ainda salientar que as distinções económicas e sociais tiveram um impacto diferencial nas oportunidades das crianças de todas as idades, integradas, por exemplo, em famílias que perderam a sua independência financeira, o que condicionou o acesso a bens alimentares e a habitação de qualidade.

Ainda que cada avaliação e intervenção devam ser adaptadas à singularidade da criança ou jovem, podemos salientar, de uma forma global, algumas medidas para a promoção da saúde física e mental destas faixas etárias.

Como já foi sublinhado, o confinamento acarreta a necessidade de as crianças e jovens estarem continuamente com os membros do agregado familiar, o que amplifica a importância dos adultos enquanto fontes de segurança. É assim crucial a promoção de momentos de atenção individual e de comunicação aberta, explorando potenciais preocupações e desconstruindo informações erróneas promotoras de ansiedade, que muitas vezes chegam sem filtro por múltiplas fontes de informação, em particular as relacionadas com a pandemia. ${ }^{1}$ Este clima de partilha e de diálogo pode ajudar na diminuição do stresse e da sensação de isolamento já descritos.

Além disso, enquanto modelos de medidas preventivas, os cuidadores também são encarregues da implementação de rotinas saudáveis para todos, incluindo horas de sono ajustadas à etapa de desenvolvimento, refeições variadas e completas, hidratação, tempo de ecrãs, atividade física, exposição solar, tempo de estudo e livre, tempo a sós (particularmente nos adolescentes) e com o agregado familiar, envolvimento nas tarefas domésticas e manutenção dos contactos sociais possíveis com a rede de suporte (grupo de pares, família alargada, entre outros; online ou por telefone). ${ }^{1,2,5}$ Este é um conjunto de medidas que foi amplamente divulgado durante o primeiro confinamento e que não pode ser descurado, dada a evidência nefasta do seu não cumprimento.

\section{REFERÊNCIAS}

1. Haleemunnissa S, Didel S, Swami MK, Singh K, Vyas V. Children and COVID-19: understanding impact on the growth trajectory of an evolving generation. Child Youth Serv Rev. 2021;120:105754.

2. Cachón-Zagalaz J, Sánchez-Zafra M, Sanabrias-Moreno D, GonzálezValero G, Lara-Sánchez AJ, Zagalaz-Sánchez ML. Systematic review of the literature about the effects of the COVID-19 pandemic on the lives of school children. Front Psychol. 2020;11:569348.

3. Rogers A, Ha T, Ockey S. Adolescents' perceived socio-emotional impact of COVID-19 and implications for mental health: results from a U.S. - based mixed-methods study. J Adolesc Med. 2021;68:43-52.
No entanto, estas novas exigências muitas vezes também trazem grande desgaste aos cuidadores, por vezes em situações socioeconómicas precárias e em burnout, que necessitam de suporte, seja em organizações da comunidade ou infraestruturas hospitalares. Esses mesmos apoios deveriam estar facilmente acessíveis e as leis laborais e de rendimento ajustadas ao contexto atual. ${ }^{1}$

Por outro lado, a nova suspensão temporária das escolas e o ensino à distância também implica que se criem normas e princípios de estudo online de qualidade, incluindo para as populações especiais que beneficiavam de apoios específicos (como o Decreto-Lei n. ${ }^{\circ}$ 54/2018 ${ }^{6}$ e frequência de terapias especializadas) e para as famílias sem acesso a tecnologias. Concomitantemente, fica premente a necessidade de supervisão dos dispositivos, de adaptação à aliteracia digital, e do apoio à comunidade escolar para criar programas atrativos e métodos educativos apropriados à faixa etária. ${ }^{1,2,5}$

Finalmente, não se podem esquecer as crianças e jovens em regimes especiais, incluindo filhos de profissionais de saúde, agregados monoparentais, residências alternadas, em acolhimento residencial, portadoras de incapacidades físicas ou mentais, que deveriam ter legislações protetoras que antecipassem as dificuldades e defendessem os seus direitos de igualdade e de acesso. Adicionalmente, as crianças vulneráveis e em risco, potencialmente expostas ao agravamento dos fatores potenciadores de maus-tratos e à diminuição dos fatores protetores nesta fase pandémica, deveriam obter particular atenção na elaboração e aplicação das leis, com o reforço das equipas de intervenção e da vigilância (não esquecendo que era nas escolas que muitas vezes se sinalizavam as situações de negligência e maus-tratos às crianças e jovens). ${ }^{1,5}$

De um modo global, embora as crianças pareçam poupadas dos impactos diretos da COVID-19, os efeitos indiretos decorrentes das situações enumeradas anteriormente, e de sistemas de saúde em sobrecarga, podem resultar em aumentos na morbilidade e mortalidade infantil a nível mundial. Assim, ainda que imprevisíveis, consideramos preocupantes as potenciais consequências desenvolvimentais decorrentes da pandemia, sendo imprescindível a vigilância por todos os envolvidos, nos cuidados às crianças e jovens, o que permitirá uma intervenção atempada.

4. López-Bueno R, López-Sánchez GF, Casajús JA, Calatayud J, GilSalmerón A, Grabovac I, et al. Health-related behaviors among school-aged children and adolescents during the Spanish COVID-19 confinement. Front Pediatr. 2020;8:573.

5. Singh S, Roy D, Sinha K, Parveen S, Sharma G, Joshi G. Impact of COVID-19 and lockdown on mental health of children and adolescents: a narrative review with recommendations. Psychiatry Res. 2020;293:113429.

6. Portugal. Decreto-Lei $n^{\circ} 54 / 2018$, Diário da República, I Série, n. ${ }^{\circ} 129$ (2018/07/06). p.2918-28. 